\title{
Thirty-two years after total right heart bypass
}

\author{
Guillermo 0. Kreutzer, MD, Buenos Aires, Argentina
}

$\mathrm{I}$ n $1971,{ }^{1,2}$ the future of patients with chronically elevated venous pressures was unknown, ${ }^{1-3}$ but the intriguing physiology of total right heart bypass was demonstrated to be compatible with life. In 1975, in Toronto, I presented "Recent Surgical Approach to Tricuspid Atresia,"4 the international experience of 35 patients with 10 hospital and 2 late deaths. After 32 years, my colleagues and I reviewed the outcome of that original cohort of patients. From communications with the pioneer cardiothoracic centers (Bordeaux, Mayo Clinic, and Chicago) included in that original paper, ${ }^{4}$ we learned that only 1 patient is still alive of the 23 survivors treated before 1975: that survivor is the fifth patient on which we operated, as presented in Toronto. ${ }^{4}$

The aim of this article is (1) to review the follow-up of our 5 survivors, (2) to explore the lessons learned over the years, and (3) to present a survival with total right heart bypass for more than 32 years, to my knowledge the longest in the world.

\section{Methods}

I conducted a retrospective review of the 5 survivors after atriopulmonary anastomosis (APA) performed before January 1975. All procedures included anterior APA, interposing a homograft between the right atrium and the pulmonary artery (PA) in 3 and using the native PA detached from the outflow tract in 2.

\section{Postoperative Evolution of the 5 Survivors Presented in $1975^{4}$}

The first patient died 8 months postoperatively owing to shrinkage of the homograft.

The second patient died in 1986, 15 years after a reoperation for resection of a dilated right atrium. The third patient had been reoperated on 2 years postoperatively owing to cyanosis resulting from an undetected coronary sinus atrial septal defect (ASD). In 1992 she was in good clinical condition, acyanotic, without arrhythmias, and with a nonpalpable liver. Follow-up information was limited because the patient was a battered woman, and in 2002 she died as a result of domestic violence.

The fourth patient had intermittent sinus rhythm and atriomegaly. Twelve years postoperatively she achieved 7 METS dur-

From the Cardiovascular Division, Hospital de Niños, and Clínica Bazterrica, Buenos Aires, Argentina.

Received for publication Jan 23, 2007; accepted for publication Feb 6, 2007.

Address for reprints: Guillermo O. Kreutzer, MD, the Cardiovascular Division, Hospital de Niños, Gallo 1330, 1425 Buenos Aires, Argentina (E-mail: gokreutzer@arnet.com.ar).

J Thorac Cardiovasc Surg 2007;134:1351-2

$0022-5223 / \$ 32.00$

Copyright () 2007 by The American Association for Thoracic Surgery doi:10.1016/j.jtcvs.2007.02.057

ing a treadmill test. Two years later she died of progressive right heart failure.

The fifth patient was operated on in January 1975 with an anterior atriopulmonary homograft (Figure 1). Follow-up was excellent: she was asymptomatic in sinus rhythm, the liver was palpable at $2 \mathrm{~cm}$, and she was receiving no medica-

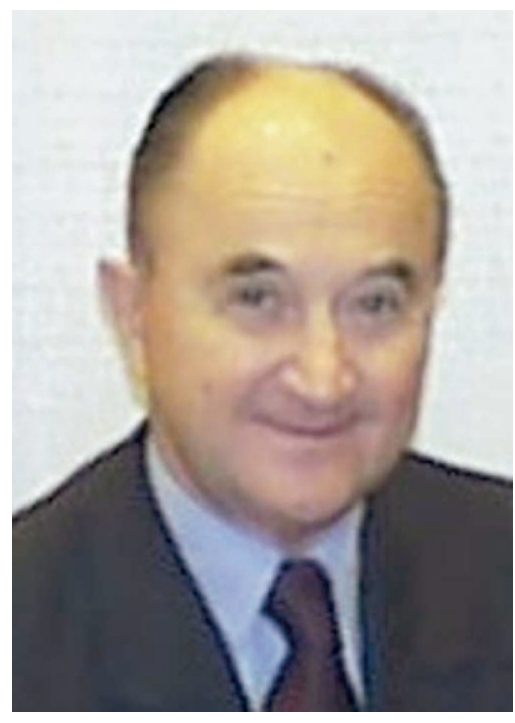

Dr Kreutzer tions. In 1998 she was treated with amiodarone for arrhythmias, alternating periods of sinus rhythm with atrial fibrillation. Anticoagulant therapy was established. She did not accept conversion until 2006, at 49 years of age, when she presented with severe decompensation, hydrothorax, intra-atrial large thrombus, but preserved left ventricular function. The lung scan disclosed homogeneous distribution of flow into both lungs.

\section{Conversion Technique of Patient 5}

Multiple clots and the calcified homograft were totally removed (Figure 2) and the distal PA was oversewn. Following the Mavroudis/Cox maze concept, intraoperative radiofrequency ablation was performed in both atria. A $22-\mathrm{mm}$ fenestrated $(3.5 \mathrm{~mm})$ polytetrafluoroethylene tube (Gore-Tex; W. L. Gore \& Associates, Inc, Flagstaff, Ariz), with the external layer removed, was used to connect the inferior vena cava orifice to the inferior aspect of the right PA, passing through the massively enlarged orifice of the superior vena cava. A Glenn shunt was performed. The postoperative course was uneventful. Pleural effusion was resolved on day 10 , and the patient was discharged on day 12 in excellent clinical condition, in sinus rhythm. Diuretics and anticoagulant therapy were maintained, and she continues to be free of symptoms 15 months after conversion.

\section{Discussion}

Most of the prerequisites for the surgery in $1975^{4}$ were correct, but not all: (1) normal pulmonary vascular resistance (correct); (2) good size PA (correct); (3) competent pulmonary valve (wrong); (4) complete closure of the ASD (wrong) (despite having performed the first successful fenestration on 1971 in our initial 2 patients, ${ }^{3}$ in the following patients we completely closed the ASD because we thought it would be beneficial); (5) small gradient between the right and left atria (correct); (6) sinus rhythm (correct); and (7) normal left heart (correct). 


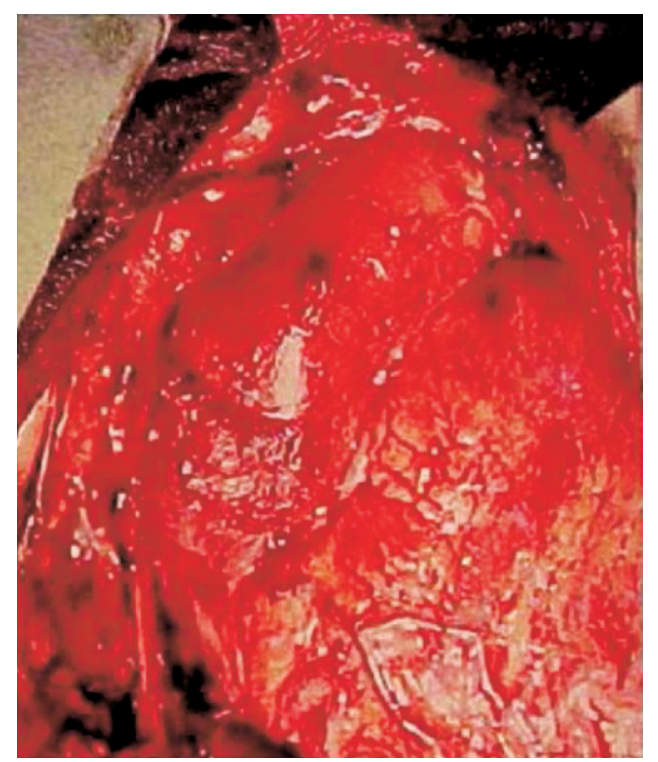

Figure 1. A fresh aortic homograft sterilized with antibiotics was placed for an anterior atriopulmonary connection at the initial operation in 1975.

We also pointed out the following ${ }^{4}$ : (1) Valves at the inferior vena cava are not necessary. "Because of the continuous venous flow (in all cases a similar M-shaped pressure tracing was found in both the right atrium and PA) we doubt that this valve would work adequately and could increase peripheral venous pressure and therefore edema." (2) "Avoid sinus node and its artery to preserve sinus rhythm." (3) "A Glenn anastomosis may benefit the newer surgical approaches." (4) "The right atrium does not function as a pump."

\section{Conclusions}

The original theories regarding total right heart bypass were mostly correct. Total right heart bypass continues to represent the best palliative option with the best long-term survival and quality of life (in this case as long as 32 years). An acceptable quality of life can be achieved when most requisites are followed. Reproduction of this setting in the majority of our patients is our challenge.

\section{References}

1. Fontan F, Baudet P. Surgical repair of tricuspid atresia. Thorax. 1971; 26:240-8.

2. Kreutzer G, Galindez E, Bono H, de Palma C, Laura JP. Una operación para la corrección de la atresia tricuspidea. Registered oral presentation at the Fifth Scientific Meeting of the Argentinian Society of Cardiology, August 1971.

3. Kreutzer G, Galindez E, Bono H, de Palma C, Laura JP. An operation for the correction of tricuspid atresia. J Thorac Cardiovasc Surg. 1973;66:613-21

4. Kreutzer G. Recent surgical approach to tricuspid atresia. In: Kidd BSL, Rowe RD, editors. The child with congenital heart disease after surgery. New York: Futura; 1975. p. 85-97.

5. Kreutzer GO, Vargas FJ, Schlichter AJ, Laura JP, Suarez JC, Rodriguez Coronel A, et al. Atriopulmonary anastomosis. J Thorac Cardiovasc Surg. 1982;83:427-36.
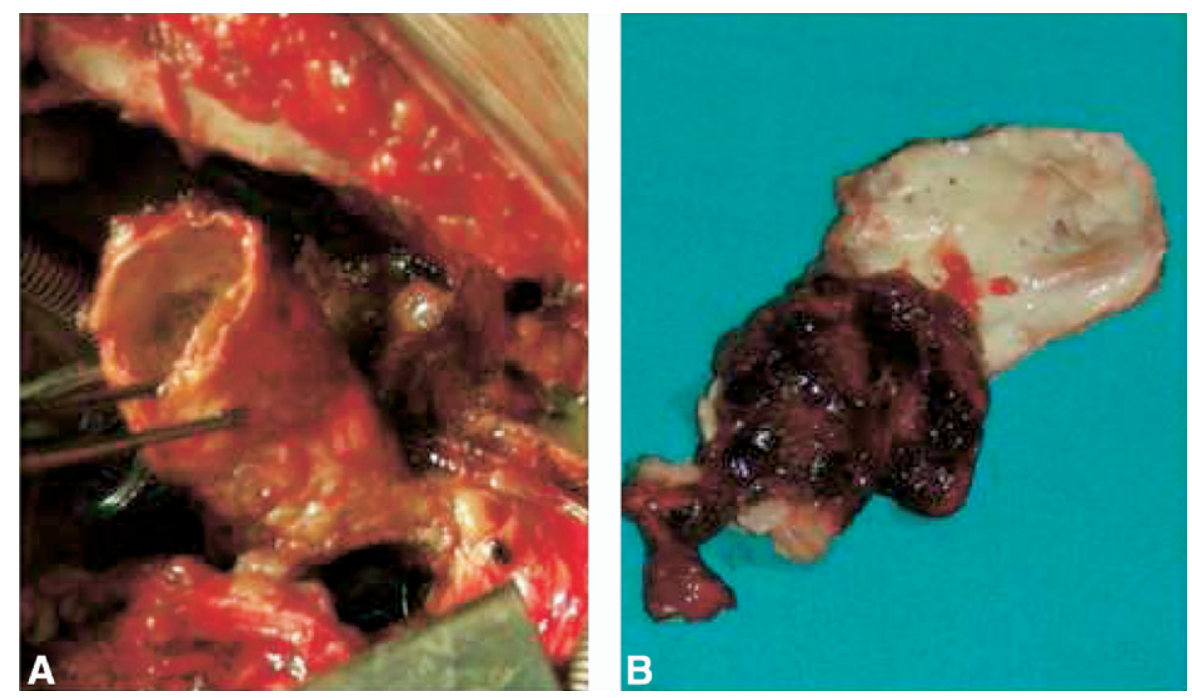

Figure 2. A, At conversion, the calcified homograft was explanted. B, Thrombus and a portion of right atrial wall were removed. 